\title{
Ehrendozent Dr. med. Johannes Karcher zum Gedenken
}

Am Sonntag, 27. April 1958, starb in Basel der Nestor der schweizerischen Medizinhistoriker, dessen jahrzehntelange, unentwegte literarische Tätigkeit ein Dankeswort in unserem bescheidenen Fachorgan rechtfertigt. Sind doch die gediegensten seiner vielen Arbeiten im Gesnerus erschienen.

JEAN KaRGHeR, wie er sich im Kreise der französischen Kirche Basel zu nennen pflegte, in der er das Amt des Vizepräsidenten bekleidete, entstammte einer Elsässer Familie und wurde am 15. Juli 1872 in Kolmar geboren. Von seiner frühen Jugend an war er dann in der alten Rheinstadt, wo er das humanistische Gymnasium besuchte. Wenige Jahre vor seinem Tode, während eines seiner häufigen Sommeraufenthalte im Solbad Rheinfelden, schreibt er (im Zusammenhang mit dem 300. Todestag von Descartes) über diese Zeit: «Als er als Medizinstudent zur Universität kam, erging es ihm ähnlich, wie es dreißig Jahre früher Theodor Kocher (siehe Sonntagsblatt vom 9. Juli 1950 der Basler Nachrichten) ergangen war, mit dem Unterschiede, daß der junge Kocher einem in den sechziger Jahren mächtig sich vordrängenden Materialismus begegnet war, der im Positivismus von Auguste Cомтe seinen schärfsten Ausdruck gefunden hatte, während zu Beginn der neunziger Jahre der dem humanistischen Gymnasium entstammende, im kirchlichen Glaubensideal unterwiesene Medizinstudent unvermittelt dem Banne eines Lehre und Forschung unumstritten beherrschenden Determinismus anheimgegeben wurde». In den Anfechtungen, die sein Kinderglaube im Umgang mit kritischen Theologen erlitt, kam ihm zugute, «daß er schon in jungen Jahren mit Descartes bekanntgeworden war, das heißt seine scharfe Trennung von Seele und Leib ermöglichte es ihm, sich über Wasser zu halten, rückhaltlos sich der deterministischen Biologie hinzugeben, ohne ihr etwas von seiner Seele preiszugeben». Alexander Vinet, der bekannte Waadtländer Theologe, und Henri Bergson hätten später geholfen, «sein religiöses und philosophisches Gleichgewicht wieder herzustellen».

In diesem Bekenntnis steht der Mann noch der letzten beiden Jahrzehnte vor uns, so wie wir ihn kennenlernen durften. Bis zu seinem Tode trotz manchem Schwerem, das er erlebte, ungebeugt, war er das Vorbild des von tiefen geistigen Strebungen geleiteten Arztes und Gelehrten, der in einzigartiger Weise eine hingebende internistische, vor allem kardiologische Praxis, mit medizinhistorischer Lehre und Forschung zu verbinden wußte. Anstelle der damals verunmöglichten Dozentur wurde er 1917 in die leitende Behörde der Universität Basel gewählt, der er bis 1933 hervorragende Dienste leistete, um dann eine Tätigkeit als Chefarzt der Inneren Abteilung am Diakonissenspital Riehen und bald darauf, im Frühjahr 1939, eine Lehrtätigkeit an der Medizinischen Fakultät als Ehrendozent für Geschichte der Medizin zu übernehmen. Diese neue Dozentenstellung war für ihn erstmals geschaffen worden, wobei wohl der bekannte Kliniker Rudolf StaE- 
HELIN den Vorschlag gemacht hatte. Vor Freunden und Kollegen hielt er bis 1947 , also bis in sein 75. Lebensjahr, Vorlesungen und ein Kränzchen ab, das auch seit seinem Rücktritt in ähnlicher Form weitergeführt wird.

Es ist erstaunlich, woher Karcher die Zeit nahm, um Woche für Woche mit einem sorgfältig ausgearbeiteten Manuskript über die verschiedensten Gebiete der Medizin aufzuwarten. Am meisten interessierten ihn entsprechend seiner unauslöschlichen Verbundenheit mit der französischen Kultur und Medizin die große Pariser Ärzteschule (vor allem Pathologen und Psychiater) und dann die gewaltige Persönlichkeit von Claude Bernard, in dem die deterministische "philosophie médicale» den nie wieder erreichten Höhepunkt erklommen hatte. Gewissermaßen als Gegenstück wählte Karcher, der noch bei CARL Ludwig in Leipzig studiert hatte, die deutschen Neurologen für weitere Studien (vor allem Romberg und Leyden). Den Anstoß zu diesen wertvollen Untersuchungen über das 19. Jahrhundert hatte ihm während einer klinischen Visite in Straßburg kein Geringerer als Bernhard Naunyn gegeben, und als Schüler von Moritz Roth (dem bekannten Vesal-Biographen, Professor für pathologische Anatomie in Basel) lernte er, wie er 1928 schreibt, « die Autoren im Urtexte sinngemäß lesen ».

Mit dem zunehmenden Interesse für die Geschichte der Medizin, das er in Basel hatte pflanzen helfen, gelangte Karcher mehr und mehr dazu, sich der Vergangenheit Basels und der Schweiz zu widmen. An erster Stelle verdient hier sein einziges eigentliches Buch erwähnt zu werden, eines der entzückendsten Werke der medizinischen Biographik im letzten Jahrzehnt: Das Lebensbild des Basler Stadtarztes Felix Platter (1949), dem leider der wissenschaftliche Apparat fehlt (aus Sparsamkeitsgründen), geschrieben mit seltener individualisierender Anschaulichkeit und Anschauungskraft. Ihm reiht sich als Frucht höchsten Alters die vor zwei Jahren erschienene Studie über den älteren Theodor Zwinger und seine Zeitgenossen an, die in den Jubiläumsschriften zum fünfhundertjährigen Jubiläum der Universität Basel erschienen ist.

In den letzten Jahren galten die Interessen unseres Vorgängers und Lehrers vor allem den Zusammenhängen zwischen Medizin und Religion. Hatte früher die umfassende Kenntnis der französischen Literatur immer wieder das Anziehende an seinen Arbeiten ausgemacht, so etwa in einem köstlichen akademischen Vortrag über «Molière und die Ärzte» (1944), so waren es jetzt Gestalten aus Zeiten von Glaubensbewegungen, wie Thomas Erastus und G. E.Stahl, die an eine frühere, ebenfalls religionsgeschichtlich orientierte Untersuchung über «die jüdischen Arztphilosophen Spaniens und Lusitaniens vom Mittelalter bis zur Neuzeit » (Gesnerus 9 [1952]) anschlossen.

Beendigen wir die knappe Skizze über unseren, mit außerordentlicher Kritik und Verstandesschärfe begabten Basler Arzthumanisten mit einem verpflichtenden Bekenntnis (Festschrift J. Brodbeck-Sandreuter, Basel 1942): «In einer Zeit des Umbaues aller Werte, des Existenzkampfes, der weitgehend'sten Speziali- 
sierung, in einer Zeit ferner, in der sich ihnen immer neue Erzeugnisse des autistisch-undisziplinierten medizinischen Denkens rechthaberisch aufdrängen, ist es dem praktischen Arzt ein Bedürfnis, sich in die heroischen Zeiten ärztlicher Vergangenheit zu versetzen, sich am Schaffen und Wirken der ärztlichen Vorfahren zu erquicken, an der Romantik ihrer Lebensläufe sich zu ergötzen.»

Die hier ausgesprochene Haltung hat Jean Karcher uns später Geborenen in Wort und Tat vorgelebt. Sein Gedächtnis wird bleiben.

H. Buess (Basel) 